\title{
Synthisophy - Integrating the Wisdoms of History into Present Culture
}

\author{
Andre Houle \\ Chicopee, Massachusetts, USA
}

\begin{abstract}
The current paper discusses the concept of synthisophy. Synthisophy is defined as the scientific integration of knowledge and wisdom derived from the study of history into the present culture. The paper provides a philosophical view on contemporary socio-political issues in the USA and reviews Chapters 1 through Chapter 15 of the original book on synthisophy. The paper's conclusions contribute to the current state of understanding of sociopolitical affairs exploring various theories such as human evolution, Argumentative Theory, Bloom's Taxonomy, and brain function.
\end{abstract}

Keywords: Synthisophy, Argumentative theory, Bloom's Taxonomy, Philosophical theory, Integration of history into culture, Politics and society

\section{Introduction}

In 1995 an article published in SKOLE, the Journal of Alternative Education, the word synthisophy first appeared (Houle 1995). The word synthisophy then appeared in the Cyclopaedic Education Dictionary (Spafford, Pesce and Grosser 1998). After the election of Donald Trump in 2016, I thought it was time to write a book, perhaps better described as an extensive research paper, about synthisophy. So, if I may introduce you to the concept.

\section{Literature Review}

Synthisophy - the scientific integration of knowledge and wisdom derived from the study of history into present culture.

- Roots - Synthesis/History/Sophy

- Synthesis - the integration of separate material or abstract entities into a single or unified whole

- History - what has happened in the past; a detailed description of past events as relating to a particular people, country, period, etc...

- Sophy - Greek root: wisdom, knowledge; an intellectual system embracing knowledge and truth; study of the real world based on fact and truth, science

The mission of synthisophy is to depolarize the USA. We presently have 2 social/political poles, the far-Right and the far-Left, with little in the middle. Here at synthisophy we are centrist. Here's some history to put this in context. With the advent of social media on the internet and the 24/7 news cycle on television, the politics of the Nation has become polarized. There have been 5 revolutions in human history: the Agricultural Revolution around 10,000 BC which led to the advent of Civilization, Science and the Age of Enlightenment, the Industrial Revolution which occurred in the late 1700s and the Digital Revolution with the advent of social media and the internet of which we are in the early stages. Television first appeared in the United States in 1928. From there by the 1940 s until the 1980 s there were three major broadcasting networks available: ABC, CBS and NBC. These three networks provided morning and evening news, while the approach among broadcasters at that time was to try and present unbiased information with 


\section{Andre Houle \\ Synthisophy - Integrating the Wisdoms of History into Present Culture}

the intent of informing the public for the betterment of society and the Nation. In 1987 the FCC eliminated the Fairness Doctrine which required broadcasters to cover controversial issues in a balanced and equitable fashion. In the late 1980s and early ' 90 s cable news networks, CNN, Fox, MSNBC, etc, started broadcasting news 24/7. Such major networks now appear to appeal to the far-Right or the far-Left in their biased presentation of news in order to increase viewership, increase advertising rates, and make more money. The internet and social media blossomed in the early 2000s which now provides information at our fingertips, and it is quite easy to have any political opinion, do an internet search, go to your preferred websites (that google has algorithmically biased you to), and instantly find information that supports that opinion. This approach is called confirmation bias. So the Digital Revolution with the advent of the internet and social media and the $24 / 7$ news cycle have led to a polarized society. This polarization is reflected in Congress in which there is little cooperation between the Democratic and Republican parties. The parties of the Left and the Right in the House and Senate have become insular and vehemently oppose each other. This polarization in the House started 25 years ago, right along with the advent of the internet, social media and the Digital Age.

Citizens are the crux of democracy, an educated and well-informed citizenry is vital for the survival of a democratic republic. As Benjamin Franklin said after exiting the Constitutional Convention and was asked what sort of government the delegates had created, his answer was, "We've given you a Republic, can you keep it?" The mission of synthisophy is to depolarize the Nation and to answer Franklin's question in the affirmative, "Yes, we can.".

\section{Research Methodology}

Here's a way to visualize the political polarization of current society. Remember the bell curve? The regular bell curve refers to a normal distribution of a value across a range. Let's look at the distribution of human height:

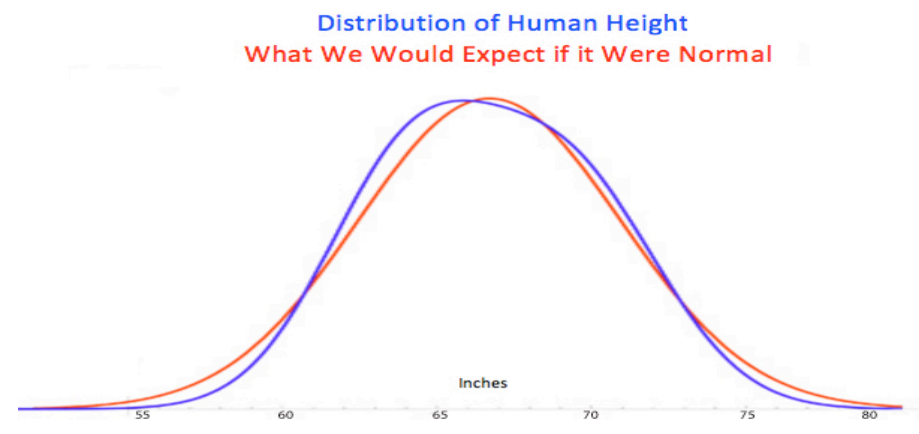

Figure 1. Distribution of Human Height. Source: www.askamathematician.com

Looking at the blue line, the average human height is about 66 inches, with a range of the number taller and shorter than the average moving down and away from the average in both directions, making the shape of a bell. Note the red curve is a perfect bell curve and is the normal distribution. So, the actual distribution of human height the blue curve, is quite close to the normal bell curve. Now let's take a look at the polarization of the population that is politically engaged, as presented in Political Polarization, 1994-2017, (Pew Research Center 2017). 
Polarization Surges Among the Politically Engaged

Distribution of Democrats and Republicans on a 10-item scale of political values, by level of political engagement Among the politically engaged

1994

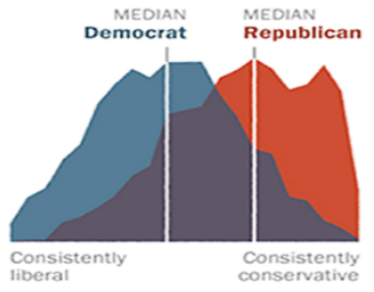

2004

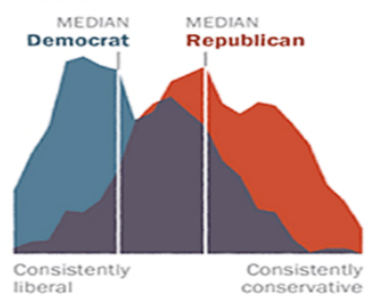

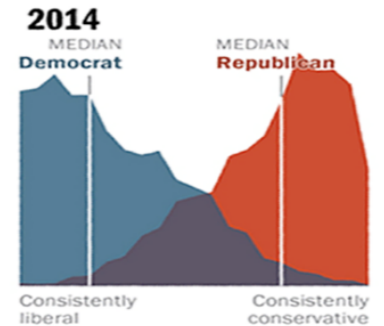

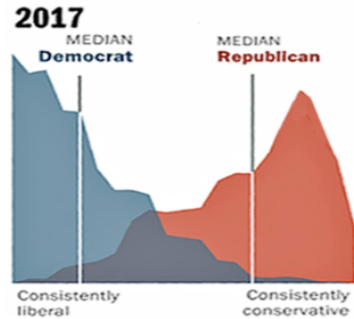

Figure 2: Polarization Surges Among the Politically Engaged

Source: www.pewresearch.org/politics/interactives/political-polarization-1994-2017/

Please look at the diagrams of the politically engaged in 1994, 2004, 2014 and 2017, notice a development over time? Note in 1994 there is no split in the curve between the Left and the Right, in 2004 we can see a split starting, by 2014 we can see an increase in polarization as the split widens, Democrats keep moving farther left, Republicans keep moving farther right. and by 2017 there's a nearly perfect upside-down bell curve! That's the exact opposite of the normal bell curve! Does that mean we're not normal? Not necessarily, but it does show just how divided and polarized, as a nation, we have become.

\section{Review of Chapters 1 Through 14}

1) Democratic Republic - a state ruled by the people through their elected representatives

2) Human Evolution - Australopithecus, Homo habilis, Homo erectus, Homo sapiens.

\section{3) Cognitive Bias}

A cognitive bias refers to a shortcut in mental thinking and decision making whereby inferences about other people and situations may be drawn in a somewhat illogical and rash fashion, but may still be highly effective in the evolutionary survival of the individual and species. Individuals create their own subjective reality from their perception of their environmental surroundings and social input.

\section{4) Confirmation Bias}

Confirmation bias is the tendency of people to favour information that confirms their existing beliefs. Confirmation bias in society, also called confirmatory bias or myside bias, is the tendency to search for, interpret, favour, and recall information in a way that confirms one's pre-existing beliefs or hypotheses.

\section{5) Argumentative Theory}

Argumentative theory claims that the function of reasoning is argumentative. It is to devise and evaluate arguments intended to persuade. Reasoning is adaptive given the exceptional dependence of humans on communication and their vulnerability to misinformation. Skilled arguers are not after the truth but after arguments supporting their views. This explains the notorious confirmation bias. (Mercier and Sperber, 2011).

\section{6) Brain Function}




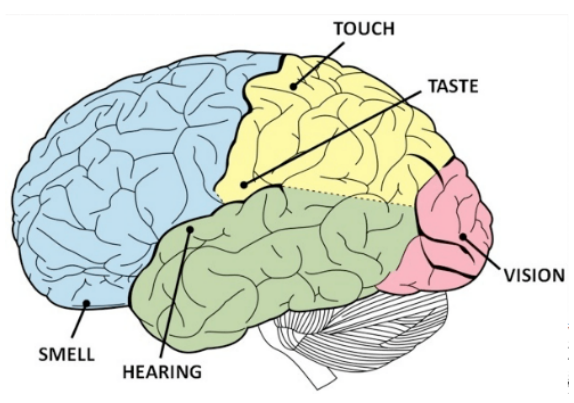

Figure 3: Brain

Source: https://buffer.com/resources/

10-surprising-facts-about-how-our-brain-works/

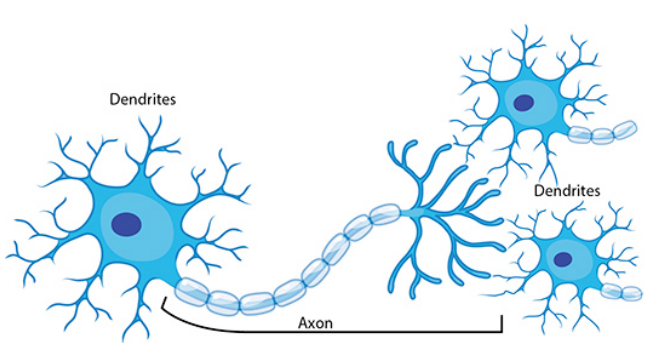

Figure 4. Neuron

Source: https://askabiologist.asu.edu/ plosable/speed-human-brain

Your brain has 100 billion nerve cells, neurons. These neurons have branching axons and dozens of dendrites that allow them to communicate with each other using various neurotransmitters. These neurons in your brain get input from our five senses, from what you see, hear, taste, touch and smell. Input from these five senses is sent via neurons and synaptic connections to get neurologically processed in your brain. With the increase in axon and dendrite terminals from branching there are approximately 1 trillion synaptic connections in your brain. These 100 billion neurons and 1 trillion synaptic connections then create the perception of your immediate surroundings, your consciousness. Another layer of processing on top of your immediate consciousness are those 100 billion neurons processing all the selected information and input you've received over your lifetime, your subconscious, to which your brain refers when consciously analyzing, categorizing, critically thinking, drawing conclusions, making daily decisions and choosing directions, from everything you've experienced and thought about in your life. That becomes your perception of reality, your neuroreality. We hope that synthisophy will bring our neurorealities closer to actual reality.

\section{7) Your Neuroreality}

Remember the 100 billion neurons in your brain that create your perception of reality, your neuroreality. Let's consider human evolution, brain function, cognitive bias, confirmation bias and argumentative theory as they may relate to neuroreality. As earlier mentioned, we evolved over the past 4 million years from Australopithecus, to Homo habilis, to Homo erectus, to Homo sapiens.

The Argumentative Theory as stated earlier explains the genetically selected human confirmation bias. A more expanded explanation of human brain development may be that the genetically selected and neurologically wired cognitive biases in early human evolution resulted in the development of confirmation biases that explain the thought processes described in Argumentative Theory. The cognitive bias present in Australopithecus lead to the confirmation bias in Homo habilis, which then could have then lead to the Argumentative Theory, an extension of confirmation bias as described above, which may have developed as Homo erectus migrated out of Africa 2 million years ago and inhabited most of Eurasia in more complex tribes and villages. This then led to Homo sapiens, their exit from Africa 70,000 years ago, and their migration and dominance over the entire world. This then led to the development of agriculture and the advent of civilization some 5000 years ago, then the industrial revolution, and now the digital revolution and information age. In the extraordinarily complex society of today, the instinctive cognitive biases, the resulting confirmation bias, applied in the argumentative theory, may all very well be present in the 100 billion neurons in your brain helping to generate your perception of reality, your neuroreality.

\section{8) Bloom's Taxonomy}




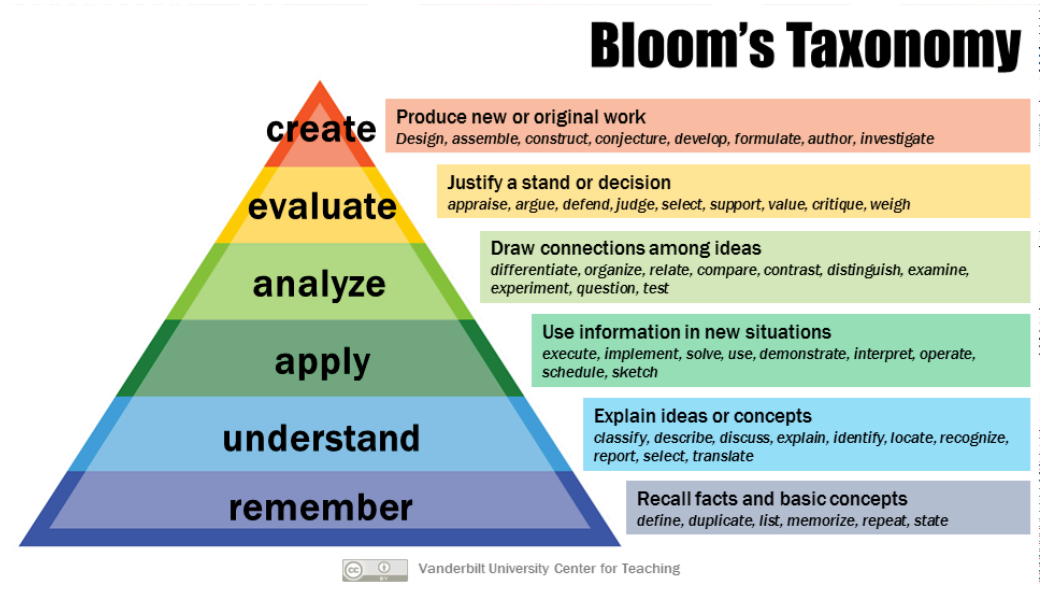

Figure 5: Bloom's Taxonomy

Source: K-12 Teaching and Learning from the UNC School of Education

\section{9) Science}

Science is the study of the real world based on fact and truth. This approach to understanding the world was initially developed in the 16th century, and this period is often called the Scientific Revolution, or the Age of Enlightenment. The scientific method is a procedure consisting of systematic observation, measurement, and experiment, and the formulation, testing, and modification of hypotheses.

\section{0) Science and Religion}

The scientific method consists of systematic observation, measurement, and experiment, and the formulation, testing, and modification of hypotheses. Note there are many questions that science can't answer, such as when did time start? Fourteen billon years ago when our universe was born in the big bang? But what was there before that? When and how did time start, or is there a start? Will time end, or is there an end? What created all the matter in the universe? Matter is made of molecules, molecules of are made atoms, atoms are made of protons, neutrons and electrons, what are protons, neutrons and electron made of? What about energy in the universe, how did that happen, when did energy start? What will happen when all available energy is spent? What created space as in the space taken up by matter and all the vacuous space of the universe? These are questions that science cannot answer, and perhaps a place for religion to answer with faith. What is good? What is evil? What is right? What is wrong? What are morals? What makes a good society? These are questions that science may provide direction but may not be able to answer fully. Recall science is the study of the REAL world based on fact and truth. To go one step further, for those questions that science can answer, perhaps science could be part of a religion. And for those questions that science can't fully answer, faith and morality could be part of that religion. Let's call that Religion. Religion - an understanding of the real world based on scientific fact and truth, but believing in the existence of God to explain the unknowable with aspects of an existing religion, or faith of one's own choice, or accepting the unknowable as God.

Perhaps God is Truth, and for questions that science can't answer, only God knows the Truth.

\section{1) The Tribe and Modern Society}

Tribe - a form of human social organization based on a set of smaller groups (bands) consisting of a small number of people (usually no more than 30 to 50 persons in all) who form a fluid, egalitarian community and cooperate in activities such as subsistence, security, ritual, and care for children and elders, and defined by traditions of common descent, language, culture, and 


\title{
Andre Houle \\ Synthisophy - Integrating the Wisdoms of History into Present Culture
}

ideology. The following are direct quotes from the book Tribe, On Homecoming and Belonging, by Sebastian Junger (2016). Westerners live in a complex society, and opportunity for scamming relatively small amounts of money off the bottom are almost endless - and very hard to catch. But scamming large amounts of money off the top seems even harder to catch. Fraud by American defence contractors is estimated at around $\$ 100$ billion per year, and they are relatively well behaved compared to the financial industry. The FBI reports that since the economic recession of 2008, securities and commodities fraud in the US has gone up by more than $50 \%$. The recession, which was triggered by illegal and unwise banking practices, cost American shareholders several trillion dollars in stock value losses and is thought to have set the American economy back by a decade and a half. Total costs for the recession have been estimated at $\$ 14$ trillion, or about $\$ 45,000$ per citizen. Most tribal subsistence level societies would inflict severe punishments on anyone who caused that kind of damage. The fact that a group of people can cost American society several trillion dollars in losses - roughly one quarter of that year's domestic product - and not be tried for high crimes shows how completely detribalized this country has become.

\section{2) Modern Crises and Tribal Instinct}

The following are direct quotes from the book Tribe, On Homecoming and Belonging, by (Sebastian Junger 2016), except for statements in italic added. What catastrophes seem to do, sometimes in the span of a few minutes, is turn back the clock on a million years of social evolution. Self-interest gets subsumed into group interest because here is no survival outside of group survival, that genetically evolved and chemically existent tribal instinct is revealed, and that creates a bond that many people sorely miss.

\section{3) The Warrior Ethos}

The following are quotes from Warrior Ethos: Analysis of the Concept and Initial Development of Application (Riccio et al., 2004), U.S. Army Research Institute for the Behavioral Sciences, September 2004, except for the last statement in italic added.

The US Army has adopted a set of army values and as a part of basic training, inculcates initial entry soldiers with their importance. The values reflect societal beliefs to which most American citizens would ascribe. Here's the Soldier's Creed with the Warrior Ethos:

\section{Soldier's Creed}

\author{
I am an American Soldier.
}

I am a Warrior and a member of a team. I serve the people of the United States and live the Army Values.

I will always place the mission first.

I will never accept defeat. I will never quit.

\section{I will never leave a fallen comrade.}

Figure 6: Soldier's Creed

Source: Warrior Ethos: Analysis of the Concept and Initial Development of Application, U.S. Army Research Institute for the Behavioural and Social Sciences, September 2004

These tenets reveal the nature of the Warrior Ethos commitment. There is an explicit commitment to one's fellow Soldiers. The tenets also imply a commitment to an organization, 


\section{Andre Houle \\ Synthisophy - Integrating the Wisdoms of History into Present Culture}

to a group whatever size is necessary to execute a mission successfully, insofar as the mission is the raison d'etre for the organization or group. The groups to which a Soldier must be committed, and that influence the Soldier's mindset, can be nested. Sometimes the commitment can be described as to a single individual, another member of a team, or to the elements within a squad, to the platoon or company with a larger operational unit, all the way up to the Army as a whole, and ultimately to the Nation. The guidance of the Combat Support Agency suggests that Warrior Ethos requires an understanding by all Soldiers of the interrelationships of such nested groups, not only with respect to the objectives that the smaller groups derive from larger groups, but also because of one's thoughts and actions in this social context increases the likelihood that one's thoughts and actions will be motivated by something larger than oneself. This Warrior Ethos above exactly describes the evolutionarily and genetically selected, and now neurologically hardwired tribal approach to survival that has resulted in Homo sapiens becoming the dominant and now the only human species on the earth.

\section{4) Soldiers Returning from Combat}

The following again are direct quotes from the book Tribe, On Homecoming and Belonging, by (Sebastian Junger 2016), except for statements in italic added. Two behaviours that set humans apart were the systematic sharing of food and altruistic group defence - this is the Warrior Ethos, this is the platoon. Other primates did very little of either, but increasingly, hominids did, and those behaviours helped set them on an evolutionary path that produced the modern world. The earliest and most basic definition of community, of tribe, would be the group of people that you would both help feed and help defend. A society that doesn't offer it members the chance to act selflessly in these ways isn't a society in any tribal sense of the word: it's just a political entity that, lacking enemies, will probably fall apart on its own. Soldiers experience this kind of tribal thinking in war, but when they come home they realize that the tribe they were actually fighting for wasn't their country, it was their unit. It makes absolutely no sense to make sacrifices for a group that itself is not willing to make sacrifices for you. That is the position American soldiers have been in for the past decade and a half. The most alarming rhetoric comes out of the dispute between liberals and conservatives, it's a dangerous waste of time because they're both right. The perennial conservative concern about high taxes supporting a nonworking "underclass" has entirely legitimate roots in our evolutionary past and shouldn't be dismissed out of hand. Early hominids lived a precarious existence where freeloaders were a direct threat to survival, and so they developed an exceedingly acute sense of whether they were being taken advantage of by members of their own group. But by the same token, one of the hallmarks of early human society was the emergence of a culture of compassion that cared for the ill, the elderly, the wounded, and the unlucky. In today's terms, that is a common liberal concern that also has to be considered. Those two driving forces have coexisted for hundreds of thousands of years in human society and have been duly codified in this country as a twoparty political system. The eternal argument over so-called entitlement programs-and, more broadly, over liberal and conservative thought-will never be resolved because each side represents an ancient and absolutely essential component of our evolutionary past, it's in our genes.

\section{Conclusion}

\subsection{Theses 1, 2 and 3}

Let us consider cognitive and confirmation bias, argumentative theory, tribal instinct and the warrior ethos from the evolutionary perspective. Cognitive bias may have been established over mammalian evolution and becoming prominent in Australopithecus 4 million years ago. Homo habilis may have evolved one step further by using confirmation bias and starting to function as a tribe. Homo erectus upon leaving Africa 2 million years ago and settling all of Eurasia may have done so with the tribe as the basic survival unit. Seventy thousand years ago, perhaps with a newly developed warrior ethos on top of the tribal instinct, Homo sapiens left Africa and conquered the world. 


\section{Andre Houle \\ Synthisophy - Integrating the Wisdoms of History into Present Culture}

As mentioned in the mission statement, at this point in time we are a very polarized Nation, which is the result of the advent of the 24/7 news cycle and social media and the internet - we have information at our fingertips. Such massive amounts of information make it very easy and almost necessary to apply a confirmation bias to selected sources that confirm that bias. The confirmation bias is an evolutionary genetic human trait, which began with the hard-wired cognitive bias neurologically developed in the brains of our ancient ancestors. We now have a neuroreality based on our hard-wired cognitive biases, which we now project with confirmation bias, that resulted in the argumentative state of mind, which is stoked by our tribal instinct and warrior ethos, which is now present in our society as evidenced by the polarization of our Nation.

\section{Thesis 1}

Maybe if we become aware of our evolutionarily selected cognitive biases that resulted in our confirmation biases, which led to the argumentative state of mind and is fired up by our tribal and warrior ethos, all of which have caused our political polarization, we can reign in these genetically selected and neurologically expressed human traits that have evolved over millions of years. Perhaps we could take a step back, try and detach ourselves from this genetic predisposition, and try and be a bit more rational rather than emotional in our political positions and discussions, seek truth rather than argument, listen, and reduce the amount of polarization and vitriol present in our society. Can we as citizens overcome this predisposition and lead our Democratic Republic as the founders intended? Recall what Ben Franklin said after exiting the Constitutional Convention when asked what sort of government the delegates had created? His answer was, "We've given you a Republic, can you keep it?" With synthisophy, the answer is yes we can.

\section{Thesis 2}

Science is the study and understanding of the real world based on fact and truth. But there are many questions that science cannot answer, which is a place for religion to answer with faith. Perhaps for those questions that science can answer, science and scientific fact and truth could be part of a religion, keeping intact those critical aspects of religion as a social institution that provides group cohesion, moral behavior and raison d'etre. To go one step further, perhaps science and the understanding of the world based on fact and truth could be part of your religion, with those questions that cannot be answered by science answered within a particular faith or your own faith - your Realigion.

Realigion - an understanding of the real world based on scientific fact and truth, but believing in the existence of God to explain the unknowable with aspects of an existing religion, faith of one's own choice, or accepting the unknowable as God.

Perhaps God is Truth, and for questions that science can't answer, only God knows the Truth.

\section{Thesis 3}

Only we the people can synthisophize: only we create and integrate the wisdoms of history into present culture.

Recall Chapter 8 on Bloom's Taxonomy (Vanderbilt University, n.d): Note that computers can process and correlate billions of bits of information per second, whereas the human brain at the consciousness level is very limited in that capacity. Also note that the human brain can integrate many pieces of related information and create new and original ideas, not just correlates. Looking at Bloom's taxonomy, computers can remember, understand, apply, analyze and even evaluate information. But at the top of Bloom's taxonomy, only the human brain can create new and original ideas integrating many pieces information from a wide variety of historic sources 


\section{Andre Houle}

Synthisophy - Integrating the Wisdoms of History into Present Culture

and come up with something completely new and of possible value to society. Restated, computers cannot and will not be able to synthisophize, integrate the wisdoms of history into present culture. Only we, the people, can do that.

\section{References}

- Houle, A. 1995. "The United States of America, A Motif for the Individual and Society." SKOLE, the Journal of Alternative Education, Summer 1995, Vol 12, No.3.

- Junger, S. 2016. Tribe, On Homecoming and Belonging. New York, NY: Twelve, Hatchett Book Group.

- Mercier, H., and D. Sperber. 2011. Why do humans reason? Arguments for an Argumentative Theory. Behavioral and Brain Sciences 34. Available at https://www.dan.sperber.fr/wpcontent/uploads/2009/10/ Crossref

- MercierSperberWhydohumansreason.pdf.

- Pew Research Center. US Politics and Policy. 2017. Political Polarization, 1994-2017, October 20, 2017. Available at https://www.people-press.org/interactives/political-polarization1994-2017/.

- Riccio, G. et al. 2004. Warrior Ethos: Analysis of the Concept and Initial Development of Application, U.S. Army Research Institute for the Behavioral and Social Sciences, Sept. 2004. Crossref

- Spafford, C., A. Pesce, and G. Grosser. 1998. The Cyclopedic Education Dictionary. New York, NY: Delmar Publishers.

- This paper was also published in the Conference Proceedings of the Research Association for Interdisciplinary Studies, August 2020.

- Vanderbilt University, Center for Teaching. n.d. Bloom's Taxonomy. Available at https://cft.vanderbilt.edu/guides-sub-pages/blooms-taxonomy/. 